\title{
PRÁTICAS DE INOVAÇÃO EM EMPRESA FAMILIAR: ESTUDO DE CASO
}

INNOVATION PRACTICES IN A FAMILY BUSINESS: CASE STUDY

Recebido em 09.01.2014. Aprovado em 22.09.2014 Avaliado pelo sistema double blind review

DOI: http://dx.doi.org/10.12712/rpca.v8i3.357

\author{
Alex Fernando Borges \\ alexfborges@gmail.com \\ Universidade Federal de Lavras - Lavras - MG - Brasil \\ Juvêncio Braga de Lima \\ juvencio.lima@fumec.br \\ Universidade FUMEC - Belo Horizonte - MG - Brasil \\ Daniela Meirelles Andrade \\ danimeirellesandrade@hotmail.com \\ Universidade Federal de Lavras - Lavras - MG - Brasil
}

\section{Resumo}

O objetivo deste trabalho consiste em compreender a construção de práticas de inovação em empresas familiares. Para tanto, foi efetuado um estudo de caso, junto a uma organização familiar do setor de cachaça artesanal, situada no Estado de Minas Gerais. A análise dos resultados permitiu verificar a construção de práticas de inovação, envolvendo um equilíbrio entre inovações de ruptura, a partir de novos produtos e métodos de produção e da exploração de novas oportunidades de negócio, e de inovações incrementais, envolvendo melhorias contínuas em atividades já desempenhadas pela empresa. Esse movimento, por sua vez, acaba por gerar possibilidades para a renovação estratégica da empresa familiar estudada, contribuindo para a sua longevidade. Conclui-se que a inovação, enquanto ação empreendedora, permite a construção de empresas familiares inovadoras, uma categoria teórica em potencial a ser explorada no campo de pesquisas sobre empresas familiares.

Palavras-chave: Empresa Familiar. Empreendedorismo. Ação Empreendedora. Inovação.

\begin{abstract}
The purpose of this paper is to comprehend the construction of innovative practices in family businesses. In order to do so, we conducted a case study in a family firm from the cachaça industry, located in the State of Minas Gerais. The results demonstrated the construction of innovative practices, involving a balance between disruptive innovations such as new products creation, new productive methods, and the exploration of new business opportunities, and incremental innovations in existing activities of the firm. This movement, in turn, generates possibilities for the strategic renewal of the family business, contributing to its longevity. We conclude that innovation, as an entrepreneurial action, allows the construction of innovative family businesses, a potential theoretical category to be explored in the field of family business research.
\end{abstract}

Keywords: Family Business. Entrepreneurship. Entrepreneurial Action. Innovation. 


\section{Introdução}

As empresas familiares são consideradas como objetos relevantes do ponto de vista econômico e social. Diversos estudos apontam para a primazia desse tipo de organização em economias avançadas e emergentes, contribuindo de maneira significativa para a geração de emprego e renda. Não obstante, as empresas familiares também tem sido objeto de teorização, uma vez que suas particularidades de natureza estratégica, gerencial e organizacional revelam um tipo de empresa que merece uma maior compreensão por parte da academia.

Atualmente, verifica-se que, apesar de se observar um nível de conhecimento mais aprofundado sobre temáticas como a sucessão, estratégia, governança e desempenho, existem tópicos que ainda não foram adequadamente explorados no campo de estudos sobre empresas familiares (BORGES; LESCURA; OLIVEIRA, 2012; LITZ; PEARSON; LITCHFIELD, 2012; SHARMA; CHRISMAN; GERSICK, 2012). Dentre essas oportunidades de pesquisa, destaca-se a exploração de aspectos vinculados à inovação,uma abordagem até então negligenciada na literatura sobre empreendedorismo e inovação (CRAIG; MOORES, 2006; ROESSL; FINK; KRAUS, 2010) se coloca como uma promissora área de pesquisa, na medida em que elementos vinculados à inovação seriam diferentes em empresas familiares e não familiares (DE MASSIS; FRATTINI; LICHTENTHALER; 2012). Cabe continuar lançando luzes sobre essa relação, contribuindo para a construção de teorias nos campos de empresas familiares, empreendedorismo e inovação (ROESSL; FINK; KRAUS, 2010).

Neste sentido, o objetivo deste trabalho consiste em compreender a construção de práticas de inovação em empresas familiares, a partir do estudo de uma organização familiar do setor de cachaça artesanal, situada no Estado de Minas Gerais. Busca-se, neste artigo, apreender ações empreendedoras de inovação desempenhadas por membros de diferentes gerações da família empresária. Esse movimento abre espaço para a configuração de uma empresa familiar inovadora, por meio de uma proposição formulada a partir da síntese de categorias teóricas elaboradas por Litz e Kleysen (2001) e Mahmoud-Jouini, Block e Mignon (2010), revelando o potencial desse quadro para o estudo da inovação em empresas familiares.

\section{Empresa familiar}

As empresas familiares são um tipo particular de organização. Uma adequada compreensão das especificidades desses objetos passa por esforços de delimitação conceitual, de diferenciação entre empresas familiares e não familiares, e de identificação de particularidades de natureza organizacional, estratégica, gerencial e familiar. Ao empreender esse movimento, seria possível entender as especificidades associadas a organizações familiares, lançando luzes sobre um tipo de empresa que vem ganhando destaque na academia ao longo das últimas décadas (SHARMA; CHRISMAN; GERSICK, 2012).

Litz (2008) ressalta que podem ser identificadas diferentes categorizações que dão suporte à definição de empresas familiares, envolvendo situações em que: a família detém a propriedade; a família é responsável pela gestão; a família detém a propriedade e é responsável pela gestão da empresa; a família fomenta a continuidade futura da organização, através da sucessão. 0 conceito apresentado por Chua, Chrisman e Sharma (1999) incorpora essas diferentes categorias, definindo empresas familiares como organizações controladas e dirigidas por uma família, com o objetivo de definir e perseguir uma visão de negócios estabelecida e potencialmente sustentável ao longo das gerações dessa família. 
Sendo assim, abre-se espaço para a consideração do processo sucessório no contexto da definição de empresas familiares. A definição apresentada por Donnelley (1964) reforça essa concepção e sintetiza diferentes elementos associados à interação entre família e organização, ao afirmar que empresas familiares são organizações identificadas com uma família há, pelo menos, duas gerações. O conceito de empresa familiar que vincula a vertente da sucessão demonstra-se como o mais apropriado para apreender a dinâmica que ocorre no âmbito de organizações familiares. Isso se dá por realçar a interação entre família e empresa a partir de uma perspectiva geracional e permitir associação com o empreendedorismo.

Com efeito, a busca por novas práticas, novos produtos e/ou serviços, novos negócios e exploração de novos mercados e ramos de atividade, que surge através da interação entre diferentes gerações da família empresária no decorrer da sucessão, gera implicações que influem sobre as possibilidades de renovação e longevidade de empresas familiares (BORGES; LIMA, 2012; NORDQVIST et al., 2013; ZELLWEGER; NASON; NORDQVIST, 2012). Nessa perspectiva, as gerações sucessoras podem manter e até mesmo superar os níveis de empreendedorismo das gerações predecessoras, oferecendo novas ideias, renovando e criando novas perspectivas para empresas familiares (DYER JR.; HANDLER, 1994). Esse movimento ocorreria a partir da participação da família em ações empreendedoras e de fomento à inovação (HOY; VERSER, 1994), envolvendo a prospecção e exploração de novas oportunidades de negócio e a melhoria contínua e a exploração estratégica de atividades já desempenhadas pela organização (WEBB; KETCHEN JR.; IRELAND, 2010).

Assim, abre-se espaço para a consideração do fenômeno da inovação em empresas familiares, a partir de ações empreendedoras de diferentes membros de famílias empresárias. Essa relação será apreendida através do resgate de diferentes conceitos sobre a inovação, vinculando-a à concepção de ação empreendedora, e da recuperação de evidências teóricas da inovação no contexto específico de empresas familiares, lançando luzes sobre essa perspectiva diferenciada nos estudos desse tipo de organização.

\section{Inovação e ação empreendedora}

A noção de inovação está no cerne da discussão do empreendedorismo, embutida nas discussões sobre a natureza da ação empreendedora (GOMES; LIMA; CAPPELLE, 2013). Para Schumpeter (1997), o empreendedor seria o agente responsável por perceber e explorar oportunidades no mercado, combinando os recursos à sua disposição de modo inovador a partir de cinco possibilidades específicas: (1) introdução de um novo produto ou de uma nova qualidade de um produto; (2) introdução de um novo método de produção; (3) abertura de um novo mercado; (4) conquista de uma nova fonte de oferta de matéria-prima ou de bens semimanufaturados; e (5) estabelecimento de uma nova organização em um setor. A partir disso, empreendedorismo e inovação seriam elementos indissociáveis e interdependentes, promovendo uma destruição criativa por meio da criação de novos produtos, tecnologias e mercados, contribuindo para o desenvolvimento econômico (SCHUMPETER, 1997).

A inovação se associa ao ato de construção de uma nova ideia, a qual poderá resultar na criação de um novo produto, serviço, tecnologia e/ou atividade em uma empresa já estabelecida (GARTNER, 1990), além de envolver novos processos, formas de organização, mercados, e o desenvolvimento de novas habilidades (ZHAO, 2005). Assim, a inovação passa a ser apreendida dentro de uma perspectiva mais ampla. Para Antoncic e Hisrich (2003) e Zhao (2005), a inovação não se encontra restrita apenas à criação de novos produtos e tecnologias. Caberia também incluir o desenvolvimento e o aprimoramento de novos e velhos produtos e serviços, 
processos e tecnologias para a execução de funções organizacionais, assim como mudanças em níveis estratégicos, organizacionais e competitivos.

A noção ampliada de inovação, na perspectiva de Panuwatwanich et al. (2009), é consistente com a pesquisa e intervenção no campo do empreendedorismo, associada a novas ideias, produtos ou processos, resultando em maior desempenho e eficiência organizacional. A inovação também se volta para uma mudança de atitude, envolvendo a resolução de problemas ou a obtenção de resultados inovadores (CABRAL et al., 2008), sendo portanto parte de um processo empreendedor, base de uma mentalidade empreendedora.

Essa característica do fenômeno tem sido associada ao próprio empreendedorismo, mas pode ser observada como elemento nucleador da dinamização de economia e regiões, agregando valor e criando necessidades de treinamento e produtos e processo complementares, alavancando dinamismo econômico. 0 empreendedorismo como fenômeno social tem em sua realidade uma interação entre empresas e agentes sociais diversos, podendo ser verificado, no caso específico da inovação, a influência do capital social, no sentido de que, uma vez identificadas as necessidades de uma dada comunidade em meio às relações desenvolvidas, as organizações saberão em o que inovar (THUHANG; JONES, 2008).

Ao avaliar o empreendedorismo como um fenômeno social, abre-se espaço para a consideração da concepção de ação empreendedora. Para Watson (2013), ações empreendedoras seriam práticas de trocas arriscadas, criativas ou inovativas entre empresas de atores empreendedores e outras partes com as quais essas empresas negociam. Segundo o autor, a ação empreendedora pode ser vista como uma categoria de criatividade situada; agir de forma empreendedora significa inovar, lidar com situações sociais e econômicas, bem como com situações que limitam e facilitam a definição de ações empreendedoras e seus resultados. Para Gomes, Lima e Cappelle (2013), a ação empreendedora envolve a produção de inovações radicais e/ou incrementais a partir de uma perspectiva multidimensional, envolvendo o empreendedor, a empresa e o ambiente. Além disso, a ação empreendedora centra o foco em ações e não no empreendedor. Interessaria verificar como os agentes agem de forma empreendedora e sua inserção em um processo maior da história e mudança social. Essa relação determina uma situação, de modo que se deve conceber que alguns atores combinam ou alternam entre agir de forma empreendedora e gerencial (WATSON, 2013).

Em mais de uma das abordagens acima expostas, torna-se claro que a ação empreendedora é parte do empreendedorismo, enquanto um fenômeno social mais amplo. E a inovação resultaria de ações empreendedoras. Algumas empresas poderiam ter maior ou menor possibilidade de desenvolverem uma orientação empreendedora e essa orientação vigoraria por meio de ações. Essas ações empreendedoras ocorreriam sempre associadas a um aspecto de transformação de empresas. No caso de empresas familiares podem ocorrer tanto por iniciativa de predecessores como de sucessores, sendo ações empreendedoras aquelas em que predecessores se relacionam com sucessores no sentido da aprendizagem daqueles que podem vir a ser responsáveis pelo futuro da empresa. A inovação sendo uma perspectiva associada à aprendizagem de processos e desenvolvimento de novos conhecimentos e processos empresariais, as ações empreendedoras podendo ser apreendidas na percepção e ação sobre oportunidades e não somente na criação de empresas, mas nesses mecanismos de transformação verificadas em função da ação em vista de aproveitar, interpretar ou mesmo criar oportunidades. Dentre os mecanismos de transformação pode-se considerar a inovação, enquanto algo que se verifica em uma prática empresarial ou organizacional, sendo, portanto, não uma representação do empreendedorismo, mas uma ação empreendedora, abrindo caminho para sua exploração e compreensão no âmbito de empresas 
familiares.

\section{Inovação em empresas familiares}

A pesquisa sobre inovação em empresas familiares constitui uma abordagem negligenciada na literatura sobre empreendedorismo e inovação (CRAIG; MOORES, 2006; ROESSL; FINK; KRAUS, 2010) e pouco explorada na literatura sobre empresas familiares (BORGES; LESCURA; OLIVEIRA, 2012; SHARMA; CHRISMAN; GERSICK, 2012). Apesar disso, é possível observar que a temática da inovação consiste em uma alternativa interessante para a pesquisa sobre empresas familiares, uma vez que fatores ligados à inovação apresentam diferenças importantes quando observados de forma comparativa em empresas familiares e não familiares (DE MASSIS; FRATTINI; LICHTENTHALER, 2013).

Uma das concepções que permite iniciar esse debate encontra-se vinculada à influência da dimensão familiar sobre a inovação. 0 envolvimento da família é considerado como um fator em potencial de influência sobre a inovação (DE MASSIS; FRATTINI; LICHTENTHALER, 2013). Não obstante, uma leitura mais cuidadosa dos trabalhos que exploram a dinâmica inovadora no âmbito de empresas familiares revela a existência de um cenário contraditório (KRAUS; POHJOLA; KOPONEN, 2012). Vários estudos abordam os efeitos e impactos da família sobre a inovação, sugerindo efeitos positivos e negativos sobre a empresa familiar, influindo sobre seu desempenho, seu sucesso e sua sobrevivência (DE MASSIS; FRATTINI; LICHTENTHALER, 2013; KELLERMANNS et al., 2012).

De acordo com Mahmoud-Jouini e Mignon (2009), os trabalhos que exploram a relação entre as características familiares do negócio e a inovação podem ser classificados em grupos distintos. Os trabalhos podem ser classificados através da ligação entre as características familiares do negócio e a inovação. Um primeiro conjunto de estudos argumenta que as empresas familiares são mais criativas, pró-ativas e inovadoras que as não familiares (CRAIG; MOORES, 2006; LLACH; NORDQVIST, 2010; KELLERMANNS et al., 2012). Um segundo conjunto de estudos sugere que as empresas familiares são caracterizadas por um certo tipo de inércia e/ou aversão ao risco, tendo o processo de inovação menos apoio que o obtido em empresas não familiares (KRAUS; POHJOLA; KOPONEN, 2012; ROESSL; FINK; KRAUS, 2010).

Por outro lado, um terceiro conjunto de estudos mostra que as empresas familiares são caracterizadas por uma cultura específica, em que empresas familiares agiriam de forma inovadora procurando manter um equilíbrio entre estabilidade e renovação. Os estudos de Mahmoud-Jouini e Mignon (2009) e de Moss, Payne e Moore (2014) demonstram que uma das principais explicações para a sustentabilidade de empresas familiares reside no equilíbrio entre tradição e renovação, geralmente possibilitada a partir de sua capacidade de inovação. Esse equilíbrio envolve, de um lado, ações empreendedoras de exploração (exploitation) de produtos/serviços/mercados já operados pela empresa, e de outro, ações empreendedoras de exploração (exploration) de novas oportunidades de negócio e novos produtos/serviços/ mercados. Assim, o envolvimento da família influi sobre a medida na qual um empresa é capaz de equilibrar exploitation e exploration (MOSS; PAYNE; MOORE, 2014), refletindo uma ambidestria (ambidexterity) de inovações incrementais e de ruptura (MAHMOUD-JOUINI; MIGNON, 2009).

Partindo dessa concepção, Mahmoud-Jouini, Bloch e Mignon (2010) apresentam o conceito de empresa familiar inovadora perene. Esse conceito é fundamentado a partir da associação de características de empresas familiares com quatro fatores chaves do processo de 
desenvolvimento de inovações: equilíbrio entre dois regimes de inovação (incremental e radical), tanto para a manutenção como para a renovação da empresa, seja de natureza sequencial e evolutiva (mudança e transformação) ou de natureza simultânea (ambidestria); capitalização e exploração/aproveitamento (exploitation) de produtos/serviços e conhecimentos existentes; exploração/prospecção (exploration) de oportunidades no mercado e desenvolvimento de novos produtos, serviços e conhecimentos, notadamente por meio de experimentação; e a criação de um contexto organizacional propício à inovação, através do envolvimento da família e de um empreendedorismo que valoriza a autonomia e a criatividade dos membros da família empresária (MAHMOUD-JOUINI; BLOCH; MIGNON, 2010).

A reunião de características familiares e de fatores chaves da inovação possibilita a configuração de um quadro de análise das capacidades de inovação de empresas familiares inovadoras perenes. O equilíbrio entre as inovações de ruptura e de melhoria contínua, revelando iniciativas de manutenção e (re)emergência organizacional por meio de ações empreendedoras de exploitation e de exploration, promoveria a renovação estratégica da empresa familiar. Verifica-se, pois, a construção de um círculo virtuoso, na medida em que características familiares permitiriam a promoção da inovação, a qual contribui para garantir a sustentabilidade da organização familiar (MAHMOUD-JOUINI; BLOCH; MIGNON, 2010).

Litz e Kleysen (2001) apontam a importância da inovação para a criação e sustentação de vantagens competitivas. A partir disso, os autores retomam o envolvimento intergeracional para estabelecer os limites de uma teoria da inovação em empresas familiares, caracterizada através da geração ou introdução intencional de novas ideias, processos, produtos e procedimentos resultantes de esforços individuais e coletivos da família empresária.

Assumindo que uma das características definidoras de empresas familiares consiste exatamente nesse envolvimento intergeracional, e que uma das facetas centrais da inovação consiste na prevenção e no estabelecimento daquilo que é novo, Litz e Kleysen (2001) apresentam a configuração de um desafio essencial: facilitar a interação criativa entre gerações predecessoras e sucessoras. Com efeito, práticas de inovação em empresas familiares podem constituir esforços independentes de membros da família, ao invés de constituir colaborações interdependentes da família empresária como um todo. Essa distinção é importante uma vez que ela sugere que a consideração de inovações a partir de sinergias entre membros da família (LITZ; KLEYSEN, 2001).

Para Litz e Kleysen (2001), a interação entre membros de diferentes gerações da família é crucial para o alcance de resultados inovadores, pois, a partir dela, seria possível construir um comportamento inovador intergeracional, contribuindo para a sobrevivência da empresa familiar. Neste caso, os autores ressaltam que, ao avaliar a inovação como um fenômeno intergeracional, gerações predecessoras e sucessoras seriam consideradas como possuidoras de capacidade e comportamento inovador, levando a empresa familiar na direção da vantagem competitiva. Sendo assim, a inovação em empresa familiar consiste na geração ou introdução intencional de novos processos e/ou produtos resultantes de esforços autônomos e interativos de membros de uma empresa familiar (LITZ; KLEYSEN, 2001).

A partir disso, verifica-se a configuração de uma teoria da inovação em empresas familiares, corroborando para a construção teórica de empresas familiares inovadoras. No caso das empresas familiares, verifica-se que surgem concepções sobre empresas familiares empreendedoras, com tentativas de conceituação, para além do simples caráter de serem ou não inovadoras. Nesse caso há concepção de empresas familiares associadas à expressão de ações 
empreendedoras, deslocando-se o centro da análise do fenômeno empreendedorismo para as ações que envolvem foco em transformações dessas empresas no sentido de sua integração em um esforço social de mudanças associadas ao empreendedorismo. A noção de ação empreendedora incorpora essas ações inovadoras diversas que podem ocorrem em uma organização familiar, servindo para configurá-la como uma empresa familiar inovadora.

\section{Procedimentos metodológicos}

Neste trabalho, utiliza-se a abordagem qualitativa de pesquisa como ponto de partida para a compreensão das práticas de inovação em uma empresa familiar. A pesquisa qualitativa, a partir de seu enfoque interpretativo da realidade (DENZIN; LINCOLN, 2000), fornece um quadro que possibilita uma compreensão mais aprofundada dos fenômenos sociais, abrindo espaço para a consideração de elementos subjetivos e simbólicos intervenientes ao contexto em estudo (GODOY, 2013). Além disso, a pesquisa qualitativa se mostra como um método mais adequado para se apreender as particularidades de empresas familiares (DAVEL; COLBARI, 2003) e para aprofundar o entendimento existente sobre a inovação nesse tipo de empresas (DE MASSIS; FRATTINI; LICHTENTHALER, 2013).

A partir da metodologia qualitativa de pesquisa, foi efetuado um estudo de caso, junto a uma empresa familiar do setor de cachaça artesanal situada no Estado de Minas Gerais, com mais de 90 anos de atuação no mercado e atualmente em uma fase de transição da quarta para a quinta geração. De acordo com Yin (2005), o estudo de caso pode ser definido como o ato de realização de uma investigação empírica que procura estudar um fenômeno contemporâneo dentro de seu contexto específico, especialmente quando os limites entre o fenômeno e o contexto não estão claramente definidos. Para Laforet (2013), estudos de caso podem gerar melhores insights de como ocorre o processo de inovação em empresas familiares.

Como técnicas de coleta de dados, foram utilizadas entrevistas em profundidade junto a membros de três gerações da família empresária estudada, a saber: predecessor (terceira geração da família empresária); predecessor (quarta geração); e dois sucessores (quinta geração). Optou-se pela técnica de entrevista por ela permitir a obtenção de dados com maior profundidade e densidade, reunindo um conjunto de evidências que possibilitam compreender o significado que os entrevistados atribuem a questões e a situações vivenciadas no contexto organizacional (GODOI; MATTOS, 2006). As entrevistas foram orientadas por um roteiro semiestruturado, e a atividade de coleta de dados foi realizada no período entre fevereiro e maio de 2013, gerando um material de 6 horas de gravação, com média de 90 minutos por entrevista. As narrativas dos entrevistados foram gravadas e transcritas em seu inteiro teor, e os nomes da empresa e dos entrevistados foram suprimidos para garantia de anonimato.

Os dados coletados por meio das entrevistas foram analisados com base na técnica de análise de conteúdo (BARDIN, 2004). O procedimento de análise envolveu a organização e a sistematização das entrevistas, de modo que termos similares pudessem ser agrupados dentro de uma mesma categoria. As entrevistas foram, então, reorganizadas em termos temáticos, envolvendo aspectos históricos da empresa familiar estudada e aspectos mais específicos, associados às práticas de inovação, revelando evidências vinculadas às categorias teóricas apresentadas por Litz e Kleysen (2001) e Mahmoud-Jouini, Bloch e Mignon (2010). 


\section{Práticas de inovação na empresa familiar do setor de cachaça artesanal Breve relato sobre a história da empresa familiar}

A história da empresa familiar estudada teve início na década de 1920, com a fabricação de cachaça em uma fazenda situada na região do Triângulo Mineiro. A atividade começou com o fundador, pioneiro da família na fabricação artesanal de cachaças, enquanto uma atividade de cunho informal, de comercialização restrita ao meio rural. Com o passar dos anos, houve, por parte do predecessor, membro da segunda geração da família, interesse em assumir o lugar do pioneiro. Inicialmente, eles tiveram grande dificuldade na comercialização da bebida, pois até então se tratava de um produto desconhecido do público. No entanto, após a inserção da cachaça em bares e pequenas mercearias, houve um aumento nas vendas e, consequentemente, na produção. Dessa forma, a cachaça passou a ser conhecida e comercializada na região do Triângulo Mineiro. Neste intervalo, houve a entrada de um novo membro da família empresária (terceira geração).

O ano de 2002 representou um marco para a história da empresa, na medida em que um dos sucessores, membro da quarta geração da família empresária, a partir de uma visão mais ampla do mercado e das oportunidades que o mesmo oferecia, optou por implantar inovações na forma de comercialização da bebida, como a utilização de novas garrafas personalizadas e, principalmente, a criação e implantação de uma marca que viabilizasse a comercialização do produto no mercado nacional. Sendo assim, após um período de transição, no ano de 2007 houve a formalização do alambique através do registro junto ao Ministério da Agricultura e Pecuária (MAPA), conforme padrões legais. Nos anos de 2008 a 2011, a primeira engarrafadora da fábrica foi montada, e no ano 2012, esta foi fiscalizada, obtendo então seu alvará de funcionamento. E foi este mesmo predecessor que, no início do ano de 2013, inaugurou a primeira loja de comercialização de cachaça, localizada na cidade de Ituiutaba, Minas Gerais. Paralelamente a esse movimento de crescimento e expansão, também ocorreu o processo entrada dos membros da quinta geração da família. Atualmente, a quinta geração também passou a fazer parte da administração da empresa, refletindo uma atuação conjunta da família no desenvolvimento do negócio.

\section{Práticas de inovação da empresa familiar}

As práticas de inovação em empresas familiares, quando colocadas em perspectiva, assumem um caráter dinâmico, revelando-se como aspecto em potencial para a longevidade dessas empresas. 0 quadro teórico aqui articulado revela essa problemática, na medida em que expõe elementos que permitem a identificação das capacidades de inovação na empresa familiar estudada, bem como as ações empreendedoras de diferentes membros da família para colocar em movimento essas inovações.

\footnotetext{
(...) a cachaça do meu bisavô começou a ser fabricada em 1922, e em 1947 o meu avô tentou a primeira abertura de firma (...). Mas aí tinha muita burocracia e aí ele desistiu, não chegou a vender com a firma, ele deu baixa. Meu pai continuou com a produção e em 2002 eu dei entrada pra requerer abertura da firma. Em 2007 foi autorizada a abertura da empresa, a indústria, a base lá na fazenda, foi aberta em 2007, e a [cachaçaria] foi aberta em 2012. Embora seja desde 1922 pra cá (Predecessor - 4ª geração).
}

Os relatos revelam, inicialmente, a trajetória da organização familiar, colocando em perspectiva a produção de cachaça artesanal como uma produção familiar, sendo transmitida de pai para filho ao longo de cinco gerações da família. Apesar de em boa parte de sua história a empresa familiar ter atuado na informalidade, isso não impediu que a mesma, a partir do empenho de 
seus membros, alcançasse um estado de perenidade por meio da qualidade do produto e sua aceitação junto ao consumidor, e de sua posterior formalização e consolidação no mercado. Essa perenidade vincula-se a diferentes processos de inovação, através da intervenção da família em produtos, processos e criação de novos negócios:

(...) Meu bisavô fabricava [cachaça] de garapa e fabricava também rapadura, açúcar mascavo... E meu avô, vendo aquilo que meu bisavô usava o melado pra fazer a rapadura, então ele ia e usava o caldo da cana antes de virar melado que era a garapa, pra poder fazer a cachaça. (...) Então ele resolveu, pensou: (...) porque não fazer o melado e do melado fazer o mosto, ao invés de fazer só de garapa. E aí ele passou a fazer e a cachaça ficou muito boa, ela era fabricada do mosto e fermentada do melado, igual todo mundo fazia do mosto fermentado da garapa e meu avô passou a fazer do mosto fermentado do melado (Predecessor - $4^{\underline{a}}$ geração).

(...) Hoje a cachaça [nome do produto] é a única cachaça no Brasil que fabrica a cachaça através do melado. 0 que é isso? A cachaça começa com a moagem da cana, faz o caldo da cana e a cada tonelada de cana tem se 500 litros de garapa, e os 500 litros de garapa vão ser fervidos na nossa produção até virar 100 litros de melado. Os 100 litros de melado vão entrar no mosto de tempero e vão produzir em torno de 80 litros de cachaça. Então de uma tonelada de cana nos produzimos 80 litros de cachaça. Aí nossa cachaça sai mais encorpada, porque ela sai do melado. (...). Então hoje o meu diferencial é esse, é o principal, é a fabricação a partir do mosto fermentado do melado do caldo da cana de açúcar (Predecessor - 4⿳a geração).

O relato do predecessor denota claramente a configuração de um produto com características inovadoras, revelando um equilíbrio entre diferentes possibilidades de inovação. De um lado, tem-se uma perspectiva de uma inovação radical, a partir da formulação de um novo método para a produção de cachaça. De outro, tem-se uma perspectiva de uma inovação incremental, uma vez que o produto resultante desse processo se constitui como um diferencial frente a outras bebidas fabricadas pelos concorrentes. Neste sentido, o processo de fabricação de cachaça de modo artesanal caracteriza um processo diferenciado, usando o melado para fazer o mosto, elemento essencial da destilação. Esse processo constitui um diferencial associado à busca de melhorias, e é por sua vez originário de um conhecimento adquirido no trabalho conjunto entre familiares e transmitido ao longo das gerações da família, podendo ser considerado como uma inovação original. Há, então, um equilíbrio entre dois regimes de inovação (MAHMOUD-JOUINI; BLOCH; MIGNON, 2010), operando de forma conjunta em prol da renovação e da competitividade da empresa familiar.

A esse equilíbrio entre diferentes perspectivas de inovação, se associam dois movimentos: a exploração/aproveitamento (exploitation) de produtos/serviços e conhecimentos existentes e a exploração/prospecção (exploration) de oportunidades no mercado e desenvolvimento de novos produtos, serviços e conhecimentos (MAHMOUD-JOUINI; BLOCH; MIGNON, 2010). Em primeiro lugar, torna-se relevante ressaltar que a base de produto, produção e sobretudo conhecimento existente na empresa familiar contribui significativamente para esse comportamento de exploitation:

(...) De 2002 pra cá, eu optei a dedicar totalmente a questão da cachaça do meu avô, por quê? Por que eu percebi que ela era uma cachaça de muita qualidade, e que se eu trabalhasse essa cachaça, se eu colocasse uma marca nela, se colocasse uma aparência nela, uma garrafa bonita, rótulo bonito, eu percebi que eu poderia colocar ela no mercado nacional. Porque ela tinha qualidade, e muita qualidade. E aí eu comecei e começou uma luta. A primeira dificuldade que eu encontrei foi para registrar o engenho, a fabricação da cachaça, e meu [bis]avô já cansado passou então à incumbência de dar continuidade à fabricação da cachaça. E eu continuei fabricando e requeri o registro junto ao Ministério da Agricultura. Foram vários anos pra conseguir e somente em 2007 que eu conseguir o registro, por que eu tive que fazer uma série de adequações. Antes o mosto, o tanque de tempero de mosto, da cachaça, era de madeira ou concreto armado e aí eu tive que coloca tudo de aço inox, os alambiques que era usado eu tive que troca pelos três alambiques 
novos. (...) A tubulação, que era todinha de PVC ou de ferro, eu tive que colocar todinha de aço inox. 0 engenho eu tive que comprar outro, por que o engenho anterior não havia vedação da saída da lubrificação da moenda, então aquela lubrificação em contato com a garapa contaminava o caldo, então foram mudanças em prol de melhorias. Mas sempre mantendo a forma artesanal (...), a mesma formar de fabricar, também do melado, as mesmas coisas, os mesmos índices que ele usava, o mesmo sistema, que ele usava até para plantar cana eu continuei e continuo até hoje e espero que não seja mudado até pra quem vem depois de mim pelos meus filhos e meus netos né? (Predecessor - 4aㅡ geração).

A cachaça produzida pela empresa familiar, um produto com mais de 90 anos de trajetória, carrega consigo um simbolismo que ilustra a própria história da família empresária. 0 produto em si incorpora essa trajetória, essa história e esse simbolismo, sendo marcado pela figura do fundador e também pela figura da família. Esse conjunto de aspectos permite posicionar a cachaça como um produto consolidado que, ao mesmo tempo, possui potencial de crescimento. A cachaça era comercializada em uma base de mercado, e marcada pela característica da informalidade. Nesse contexto, o predecessor da quarta geração identificou que, a partir de "uma cachaça de muita qualidade", era possível ampliar seu mercado de atuação, "se colocasse uma marca, uma garrafa bonita, um rótulo bonito". Além disso, o predecessor também procurou formalizar as atividades produtivas da empresa familiar, por meio da obtenção de registro do produto junto ao Ministério da Agricultura. Verifica-se que a empresa teve que adaptar seus processos de produção dado a exigências legais, envolvendo, em todo processo gerencial necessário dado a essas exigências legais e também a inovação tecnológica. Esse conhecimento de exigências legais foi fundido nesse processo de capitalização, constituindo em si mesmos um conjunto inovador, pela tradição de fabricar a cachaça com certa particularidade e pela modernização tecnológica do processo de fabricação.

Registra-se ainda o reconhecimento de que havia um conhecimento a ser aprendido, pela prática direta da atividade. Houve capitalização do conhecimento existente e posteriormente uma exploração desse conhecimento: de um lado, havia o reconhecimento de que a cachaça era especial, pelo seu modo de fabricação e isso poderia ser um diferencial no processo de modernização associado à efetiva empresarização do negócio, envolvendo os aspectos técnicolegais necessários, representando, em si mesmo, a inovação necessária. De outro lado, essa interpretação trazia embutida consigo a exploração de um conhecimento existente. Há acumulação de competências pela prática continuada dos agentes na atividade principal, em um processo contínuo de aprendizagem organizacional. A exploração de conhecimentos existentes exigiu o reconhecimento de formação de competências e aprendizagem intergeracional. Isso se verifica na modernização da empresa pela legalização de seu produto principal, e pela organização empresarial, em termos de distribuição de funções e agregação de melhorias aos processos de produção e comercialização da bebida. Esses movimentos revelam, pois, uma ação empreendedora de inovação incremental, modificando parâmetros do produto e do processo de produção e assim promovendo melhorias contínuas sobre a base organizacional existente.

Paralelamente, verifica-se também a exploração de novas oportunidades de negócio e de novos produtos e processos (MAHMOUD-JOUINI; BLOCH; MIGNON, 2010):

Por detrás da cachaça em si, tem uma série de produtos que são fabricados da cachaça. (...) Inclusive, lançamos uma série, uma linha de geleias fabricada a partir de cachaça. Geleia com cachaça, geleia de cachaça com gengibre, geleia de cachaça com pimenta e geleia de caipirinha (Predecessor - 4⿳亠丷厂 geração).

Criamos [novos produtos]. (...) Temos a pinga, a cachaça em forma de frutas (...), ela é feita porque as pessoas então carentes de novidades, entendeu? E nem todo mundo gosta de 
uma cachaça, você chegar e tomar uma cachaça. A gente criou uma caipirinha, a gente criou esse mix de pinga com fruta que é o maracujá, fez com o morango, no kiwi, no caju, na jabuticaba, no murici e aí tomou uma proporção que tá todo mundo sabendo já. Tem o licor de café, amarula, tem licor de jabuticaba, licor de laranja, licor de chocolate com pimenta, tem geleia também de chocolate com pimenta, laranja, de caipirinha também (Sucessor 1 - 5 a geração).

(...) da cachaça, eu já fiz balinha de cachaça, já fiz bolo de cachaça e... bolo de caipirinha, torta... Coisa que ninguém nunca tinha visto no mercado, ninguém tinha visto. (...) Isso é a minha visão, que sempre tem que esta mudando e melhorando pra estar chamando atenção (Predecessor $4^{\mathrm{a}}$ geração).

Esse caso, em que uma família torna-se presente em vários aspectos de decisão e ação ao longo da construção da empresa, revela uma aprendizagem contínua na exploração e desenvolvimento de novos conhecimentos. Com efeito, o próprio produto é oriundo de um método inovador de produção, o qual, segundo o predecessor da quarta geração da família empresária, constitui a "única cachaça no Brasil [fabricada] através do melado". Essa característica inovadora do produto revela um processo de inovação de ruptura, em que uma nova técnica de produção resulta em um produto diferenciado no mercado. Ao mesmo tempo, a família empresária tem efetuado diferentes ações empreendedoras de inovação, vinculadas à criação e lançamento de novos produtos no mercado. Neste contexto, produtos como geleias, licores, caipirinhas e caipifrutas, todos de alguma forma derivados da cachaça, revelam iniciativas claras de execução de processos inovadores marcados pela interação entre diferentes gerações da família empresária.

A cada passo novas soluções levavam a empresa a outro patamar de desafios empresariais, desafios estratégicos que exigiam novas reflexões pelos dirigentes, sempre com renovação inovadora com efeitos significativos de consolidação e criação de novos desafios gerenciais. A história revela vários fatos verificados ao longo da história da empresa. Esses desafios se dão na progressiva transformação da forma de comercialização, na abertura de um novo negócio, e na busca de ações de marketing visando ampliar a difusão do produto e consequente entrada em novos mercados:

A gente procurou montar uma loja que fosse adequada a cachaça e que fosse bem visível, que fosse bem estruturada, uma loja em que o consumidor pudesse chegar e falar: 'não essa loja ficou bonita'. Então a gente procurou fazer isso, (...) a única [cachaçaria] da região (Predecessor - 4ํㅡ geração).

Eu entendo que a cachaça é a bebida do momento, porque ela tem muita perspectiva de saída do mercado, e sobretudo agora, a caipirinha que tem sido um grande produto no mercado nacional e que chama atenção dos estrangeiros (...). Ano que vem, que é o ano da copa, pra cada cidade sede a gente possa ter um representante nosso pra poder vender a nossa caipirinha para o estrangeiro. Então é por isso que eu entendo que é um mercado muito promissor (Predecessor - $4^{a}$ geração).

Nós estamos agora concluindo o lançamento da fase da geleia, e em seguida agora vamos concretizar o lançamento da caipirinha, e em seguida vamos começar a exportar para o exterior a nossa cachaça, a caipirinha, todos os produtos do [nome da empresa]. (...) A gente tem intenção em exportar, para os países da América do sul, para América do Norte, Estados Unidos, Cuba e para Europa. Esse é o nosso objetivo agora (Predecessor - $4^{\underline{a}}$ geração).

Assim, verifica-se a exploração de novas oportunidades de negócio. De um lado, houve a abertura de uma loja específica (cachaçaria) para a comercialização da cachaça fabricada empresa familiar, constituindo um dos únicos empreendimentos especificamente voltados para 
a venda de cachaça na região do triângulo mineiro. A empresa familiar, nesse sentido, estabelece como objetivos estratégicos a entrada e o acesso a novos mercados, planejando aproveitar os grandes eventos que ocorrerão no Brasil para difundir a marca da cachaça. De outro lado, há um objetivo de internacionalização da marca, visando aproveitar as oportunidades e o simbolismo representado pela cachaça em outros países via iniciativas de exportação. Com isso, demonstrase uma preocupação constante com perspectivas de longevidade, imbricada a essas ações empreendedoras inovadoras, revelando a criação de um ambiente propício à inovação (MAHMOUD-JOUINI; BLOCH; MIGNON, 2010):

Assim, verifica-se a exploração de novas oportunidades de negócio. De um lado, houve a abertura de uma loja específica (cachaçaria) para a comercialização da cachaça fabricada empresa familiar, constituindo um dos únicos empreendimentos especificamente voltados para a venda de cachaça na região do triângulo mineiro. A empresa familiar, nesse sentido, estabelece como objetivos estratégicos a entrada e o acesso a novos mercados, planejando aproveitar os grandes eventos que ocorrerão no Brasil para difundir a marca da cachaça. De outro lado, há um objetivo de internacionalização da marca, visando aproveitar as oportunidades e o simbolismo representado pela cachaça em outros países via iniciativas de exportação. Com isso, demonstrase uma preocupação constante com perspectivas de longevidade, imbricada a essas ações empreendedoras inovadoras, revelando a criação de um ambiente propício à inovação (MAHMOUD-JOUINI; BLOCH; MIGNON, 2010):

\begin{abstract}
Ai eu pensei e agora eu posso vender, e o [fiscal do Ministério da Agricultura] disse ainda não ele falou que eu tinha que abrir uma engarrafadora, porque você tem que ter a indústria, e tem que ter a engarrafadora e o produto para ser engarrafado. Toda a linha de produção ou você abre a engarrafadora ou você contratar a terceira, uma empresa terceirizada que mexa com engarrafamento para engarrafar seu produto, e ai eu pensei eu cheguei ate aqui eu não vou fazer isso e ai comecei a minha luta para montar a engarrafadora. Eu, minha esposa, meus filhos, meu pai... ajudando e aí comecei a luta para montar a engarrafadora, montando a engarrafadora de 2008 ate 2011 em dezembro de 2011 eu concluí a montagem da montadora definitivamente... (Predecessor - $4^{\underline{a}}$ geração).
\end{abstract}

0 relato revela que a formalização do negócio, enquanto uma atividade que pode ser vista inicialmente de uma perspectiva operacional e necessária à produção e comercialização do produto, na verdade sedimenta o espaço para um crescimento mais robusto e consistente da empresa familiar, gerando a motivação para que seus diferentes membros possam buscar novas possibilidades para si mesmo e para a organização, configurando um ambiente organizacional propício à inovação, envolvendo ações estratégicas e empreendedoras:

Eu aqui dentro da empresa estou como colaborador, proprietário... Como colaborador principal né? Eu tenho a função hoje de organizar, coordenar e sugerir algumas coisas que tem que ser feitas, pra um bom andamento eu juntamente com a minha esposa, tem meu pai, então em conjunto a gente dita a fórmula que a gente acha que deve caminhar, porque tem que ter, toda empresa tem que ter o norte, uma pessoa que direciona, se não ela fica como um barco se vela. Então hoje a minha postura aqui dentro é de direcionamento, da realização empresarial e sugerir ideias novas, não só eu, mas minha esposa, meus filhos, meu colaboradores, a gente considera aqui os funcionários nosso aqui como se fosse da família (...) então a gente tem esse contexto de ser muito sociável com quem trabalha junto conosco. (...) 0 empreendedorismo é isso, é ter ideias novas, é se lançar para frente, é buscar sempre algo novo com visão de negócio, visão de futuro e nunca ter medo de acertar e nem de errar. Mas, também tem que ser aquela coisa assim consciente, uma coisa seria e pensada, entendeu? E se, pensar assim pode dar certo e pode não dar certo, bom o risco é maior que o benefício então eu vou embora. Então se o beneficio é maior então vamos arriscar (Predecessor - $4 \stackrel{\text { a }}{\text { geração). }}$ 
Verifica-se que a configuração de um ambiente organizacional propício à inovação perpassa diferentes possibilidades de inserção, participação e autonomia dos membros da família empresária. Com efeito, predecessores e sucessores atuam de forma conjunta, sugerindo novas ideias e gerando novas perspectivas para a empresa familiar, a partir de ações empreendedoras de inovação incremental e de inovação radical, em uma relação dinâmica que garante, de forma simultânea, o surgimento de inovações incrementais e de inovações radicais, o aproveitamento e melhoria contínua das atividades já desempenhadas e a exploração de novos produtos, processos e oportunidades de negócio. Isso, evidentemente, não é dissociado do caráter intergeracional, visando prover a continuidade da empresa familiar para futuras gerações da família:

\begin{abstract}
Eu vejo o futuro [dos filhos] como o futuro da própria empresa, porque eu penso que a cachaça é um mercado muito promissor, para o futuro e se eles procurarem fazer bem feito e procurarem fazer de forma honesta e assim de tudo com humildade, eles tem um grande futuro pela frente e a empresa, por que essa empresa tem tudo pra crescer de forma impressionante. Então tem que ser bem feito, com perseverança e humildade sem pisar em ninguém e sem maltratar ninguém, mais todos os dias trabalhando de manha até a noite, sempre procurando coisa nova, é... Procurar alavancar o nome, a marca e a imagem da empresa e a qualidade da cachaça, mantendo a qualidade da cachaça (Predecessor - $4^{\mathrm{a}}$ geração).
\end{abstract}

A criação desse espaço organizacional propício à inovação gera, de forma complementar, implicações para a própria continuidade futura da empresa familiar. Na verdade, um espaço que garanta a socialização, o envolvimento, a participação e a autonomia, para que sucessores possam ter liberdade para desempenhar seus papeis no âmbito da organização, contribui para que os mesmos assumam responsabilidades e passam a buscar, junto com os predecessores, por aspectos como renovação, competitividade e longevidade do negócio da família, transformando aspectos que até então se manifestavam de forma isolada em uma rede imbricada de significados que sintetizam a dinâmica da interação entre indivíduos, família e empresa, configurando uma inovação intergeracional e a construção de uma empresa familiar inovadora.

\title{
Inovação intergeracional e a construção da empresa familiar inovadora
}

A análise sobre as capacidades de inovação da empresa familiar estudada revela um equilíbrio entre diferentes regimes de inovação, entre a exploração e aproveitamento contínuo de atividades já consolidadas e a exploração e prospecção de novas oportunidades de negócio, e a criação de um ambiente organizacional propício para a inovação. Não obstante, essas capacidades, quando colocadas na perspectiva da empresa familiar estudada, não podem ser dissociadas de um caráter intergeracional, o qual sintetiza diferentes ações empreendedoras observadas no âmbito da organização familiar.

Primeiramente, observa-se a configuração de um processo de inovação intergeracional, envolvendo a interação entre membros de diferentes gerações da família empresária para a produção de cachaça por meio de um método não utilizado no setor. Nota-se a visão do predecessor em criar um produto único, pioneiro no mercado, através da observação da atuação e práticas de produção até então desempenhadas na empresa, bem como por meio do conhecimento compartilhado entre membros de diferentes gerações da família empresária. Tanto alterações em produtos como em processos revelam esse caráter inovador, e o resultado disso pode ser explicado a partir da interação entre família e empresa: 
(...) chegou um momento na empresa em que eu percebi que eu já não conseguia mais suprir todas as necessidades da empresa sozinho, eu não dava conta mais de tomar conta tudo sozinho e minha esposa e meu filhos já ajudavam muito, mais ai eu percebi que eu precisava de dar mais funções pra eles, e ai eu comecei a dar mais funções pra eles, pra minha esposa e pro meus filhos e de repente eu vi que já não bastava, que eu tinha que colocar mais gente e isso foi crescendo... é... até de forma natural; foi envolvendo mais gente e o que me dar uma satisfação muito grande é que eu percebo que há dez anos atrás (...) era indispensável que a cachaça continuasse viva, que a empresa continuasse viva, e hoje eu já não sou mais indispensável se eu não tiver aqui hoje ou amanhã isso aqui ficou de um tamanho e de uma qualidade que ela anda por si só. Outra pessoa aqui no meu lugar consegue tocar a cachaça tão bem, ou talvez melhor do que eu (Predecessor - 4á geração).

Os processos inovadores promoveram mudanças e transformações a partir de ações de melhoria contínua em produtos e processos existentes, e a partir da exploração de novas oportunidades de negócio, do lançamento de novos produtos e da abertura da cachaçaria. 0 predecessor, neste sentido, revela a importância e a necessidade da participação da família na empresa familiar. Pode-se observar que o envolvimento da família e a contribuição obtida por meio de sua atuação e interação no desenvolvimento das atividades de produção, comercialização e gestão da empresa familiar, denota possibilidades de caracterização de uma empresa familiar inovadora, revestida de um caráter de inovação intergeracional que abre novas perspectivas para a perenidade da empresa, incluindo aí a sobrevivência do negócio, sua competitividade e permanência no âmbito da família empreendedora:

Quando eu engarrafava com aquele rótulo que eu te disse [alambique informal], a gente tinha uma linha de produção: meus dois filhos lavavam as garrafas e desinfetavam e eu enchia e minha esposa colocava rótulo. Então desde daquela época todo mundo já trabalhava junto, todo mundo já se ajudava, a gente era uma empresa disfarçada em família, ou uma família disfarçada em empresa (Predecessor - 4aㅡ geração).

(...) de vez em quando a gente junta a família e fala, a gente tem que ter uma nova ideia. Igual a cachaça com fruta, a caipirinha, foi uma ideia da família, até meu pai... Mas a gente tenta dar ideia pra buscar uma coisa nova pra aceitação do público (Sucessor 2 - 5 geração).

Assim, verifica-se que a atuação conjunta de membros de diferentes gerações da "família disfarçada em empresa", modifica e transforma a realidade da "empresa disfarçada em família". 0 relato reforça a perspectiva interacional, revelando a construção de um ambiente propício à inovação. Na verdade, o fato de reunir a família para a busca de novas ideias, reveste a empresa familiar como um espaço para a cocriação da inovação, a partir de um efetivo comportamento inovador intergeracional. Esse comportamento, por sua vez, ressignifica as ações de predecessores e sucessores para mudar e transformar a organização, gerando implicações em produtos novos e/ou melhorados, em processos produtivos reformulados, no atendimento de novos mercados, no estabelecimento de estratégias futuras de crescimento, dentre outras possibilidades. Esse conjunto de evidências, por fim, forma o círculo virtuoso de exploração de atividades já estabelecidas e de novos produtos e práticas organizacionais, mencionado por Mahmoud-Jouini, Bloch e Mignon (2010) e reforçado por Moss, Payne e Moore (2014). Adicionalmente, ao incorporar a perspectiva inovadora intergeracional exposta por Litz e Kleysen (2001), tem-se a construção da empresa familiar inovadora enquanto categoria teórica, mas que, do ponto de vista prático, revela interessantes implicações em termos de perspectivas de sua perenização e sustentabilidade. 


\section{Considerações finais}

Nesse trabalho, procurou-se compreender a construção de práticas de inovação em uma empresa familiar. Para tanto, foi estruturado um quadro de análise com base nas formulações de Mahmoud-Jouini, Bloch e Mignon (2010), envolvendo a problematização de empresas familiares inovadoras perenes, e na concepção de inovação intergeracional de Litz e Kleysen (2001). A elaboração teórica compreendeu o diálogo com diferentes autores que discutiam o fenômeno da inovação e, em especial, a inovação em empresas familiares. Essa problemática foi associada com a perspectiva conceitual aberta pela noção de ação empreendedora, considerada como elemento nucleador do fenômeno empreendedorismo, fixando as práticas efetivas, aquilo que o empreendedor efetivamente faz, centrando o foco na ação e não no empreendedor em si (WATSON, 2013; GOMES; LIMA; CAPELE, 2013). Em especial, a ação empreendedora foi considerada como presente tanto na busca, identificação ou construção de oportunidades, como em processos empresariais de implantação de atividades, dentre as quais se inclui a inovação, bem como nos resultados dessas atividades inovadoras, sempre ponto de partida de novas ações.

Nessa perspectiva, foram construídas cinco categorias para observar o fenômeno da inovação em empresas familiares: equilíbrio entre inovações de ruptura e de melhoria contínua; capitalização e exploração de inovações existentes; exploração e desenvolvimento de novos conhecimentos, produtos e processos; e criação de um contexto organizacional propício à inovação e inovação intergeracional.

O estudo de caso permitiu a verificação de práticas de inovação ao longo da história da empresa e uma dinamização recente, na fase atual de comando compartilhado entre a quarta e quinta geração da família empresária, configuradas em diferentes ações empreendedoras. Fabricar cachaça a partir do melado foi uma técnica inovadora na origem do empreendimento, uma inovação de ruptura. Essa característica foi o ponto de partida para inovações de melhoria contínua, que perpassa várias fases de modernização do empreendimento: a legalização da empresa, com consequente ajustes das instalações e do processo produtivo, a mudança no processo de comercialização, incluindo ações de marketing e iniciativas de entrada em novos mercados de entradas e internacionalização via exportação do produto.

As ações empreendedoras de inovações contínuas revelaram a construção de uma perspectiva de longo prazo, acompanhadas de construção de competências pelo grupo familiar envolvido diretamente com a produção e gestão empresarial. 0 conjunto de processos decisórios associados à modernização da atividade - produção e comercialização de cachaça - foi acompanhado de aquisição de novos conhecimentos e novos desafios de domínio de técnicas de produção e administrativas. De um lado, verificou-se a capitalização de conhecimentos existentes, dominados pela prática anterior e o domínio de novos conhecimentos. Assim, ocorreu com a abertura de um novo negócio, a criação de novos produtos, o envolvimento efetivo da família na atividade empresarial e toda aprendizagem associada à implantação de técnicas de marketing e exploração de novos mercados.

Associado à tradição que conferia um valor à marca da cachaça, pelo seu diferencial de gosto e agregação de valor pelo processo industrial diferenciado, verificou-se uma intensificação de interação entre predecessores e sucessores, identificando-se não somente uma interação real, mas também potencial. Isso resultou em iniciativas estratégicas e gerenciais, aprendidas e desenvolvidas ao longo do tempo. A inovação torna-se uma ação empreendedora familiar, configuradas nesse caso, como práticas de inovação intergeracional. 
Portanto, foi possível compreender a construção de práticas de inovação, envolvendo um equilíbrio entre inovações de ruptura, a partir de novos produtos e métodos de produção e da exploração de novas oportunidades de negócio, e de inovações incrementais, envolvendo melhorias contínuas em atividades já desempenhadas pela empresa, e a criação de uma empresa familiar aberta à inovação. Esse movimento, por sua vez, acaba por gerar possibilidades para a renovação estratégica dessas empresas, contribuindo para a sua longevidade. Assim, a inovação, enquanto ação empreendedora, permite a construção de empresas familiares inovadoras. Esse conjunto de concepções possibilita a observação do vigor da manifestação do fenômeno do empreendedorismo em organizações familiares, abrindo espaço para futuros estudos sobre esses objetos e configurando uma perspectiva teórica em potencial a ser explorada no campo de pesquisas sobre empresas familiares.

\section{Referências}

ANTONCIC, B.; HISRICH, R. Clarifying the intrapreneurship concept. Journal of Small Business and Enterprise Development, v.10, n.1, p.7-24, fev. 2003.

BARDIN, L. Análise de conteúdo. 3. ed. Lisboa: Edições 70, 2004. 223 p.

BORGES, A. F.; LESCURA, C.; OLIVEIRA, J. L. O Campo de Pesquisas sobre Empresas Familiares no Brasil: Análise da Produção Científica no Período 1997-2009. Organizações \& Sociedade, v. 19, n. 61, p. 315-332, jun./ago 2012.

BORGES, A. F.; LIMA, J. B. O Processo de Construção da Sucessão Empreendedora em Empresas Familiares: Um Estudo Multicaso. Revista de Empreendedorismo e Gestão de Pequenas Empresas, v. 1, n. 1, p. 131-154, jan./abr. 2012.

CABRAL, G. G.; TABOSA, T. C. M.; TSCHA, E. R.; CAVALCANTI, V. P. Intra-empreendedorismo, design e inovação: um caso de parceria universidade empresa. In: ENCONTRO DE ESTUDOS SOBRE EMPREENDEDORISMO E GESTÃO DE PEQUENAS EMPRESAS, 5., 2008, São Paulo. Anais... São Paulo: EGEPE, 2008.

CHUA, J. H.; CHRISMAN, J. J.; SHARMA, P. Defining the family business by behavior. Entrepreneurship: Theory \& Practice, v. 23, n. 4, p. 19-39, dez. 1999.

CRAIG, J. B. L.; MOORES, K. A 10-Year Longitudinal Investigation of Strategy, Systems, and Environment on Innovation in Family Firms. Family Business Review, v. 19, n.1, p. 1-10, mar. 2006.

DAVEL, E.; COLBARI, A. Organizações familiares: por uma introdução a sua tradição, contemporaneidade e multidisciplinaridade. Organizações \& Sociedade, v. 7, n. 18, p.45-64, 2000.

DE MASSIS, A.; FRATTINI, F.; LICHTENTHALER, U. Research on Technological Innovation in Family Firms: present debates and future directions. Family Business Review, v. 26, n. 1, p. 1031, jan. 2013.

DENZIN, N. K.; LINCOLN, Y. S. Handbook of Qualitative Research. 2. ed. Thousand Oaks: Sage Publications. 2000.

DONNELLEY, R. G. The family business. Harvard Business Review, v. 42, n. 4, p. 94-105, 
jul./ago. 1964.

DYER Junior, W. G.; HANDLER, W. Entrepreneurship and family business: exploring the connections. Entrepreneurship: Theory \& Practice, v. 19, n. 1, p. 71-83, jan. 1994.

Gartner, W. B. 'What are we talking about when we talk about entrepreneurship?' Journal of Business Venturing, v.5, n.1, p.15-28, mar. 1990.

GODOI, C. K.; MATTOS, P. L. C. L. de. Entrevista qualitativa: instrumento de pesquisa e evento dialógico. In: GODOI, C. K.; BANDEIRA-DE-MELLO, R.; SILVA, A. B. da (Org.). Pesquisa qualitativa em estudos organizacionais: paradigmas, estratégias e métodos. São Paulo: Saraiva, 2006. p. 303-323.

GODOY, A. S. Fundamentos da Pesquisa Qualitativa. In: TAKAHASHI, A. R. W. (Org.). Pesquisa Qualitativa em Administração: fundamentos, métodos e uso no Brasil. São Paulo: Atlas, 2013. p. 35-50.

GOMES, A. F.; LIMA, J. B.; CAPPELlE, M. C. A. Do Empreendedorismo à Noção de Ações Empreendedoras: Reflexões Teóricas. Revista Alcance, v. 20, n. 2, p. 203-220, abr./jun. 2013. HOY, F.; VERSER, T. G. Emerging business, emerging field: entrepreneurship and the family firm. Entrepreneurship: Theory \& Practice, v. 19, n. 1, p. 9-23, jan. 1994.

KELLERMANNS, F. W.; EDDLESTON, K. A.; SARATHY, R.; MURPHY, F. Innovativeness in family firms: a family influence perspective. Small Business Economics, v. 38, n. 1, p. 85-101, jan. 2012.

KRAUS, S.; POHJOLA, M.; KOPONEN, A. Innovation in family firms: an empirical analysis linking organizational and managerial innovation to corporate success. Review of Managerial Science, v. 6, n. 3, p. 265-286, jul. 2012.

LAFORET, S. Innovation characteristics of young and old family-owned businesses. Journal of Small Business and Enterprise Development, v. 20, n. 3, p. 204-224, jan. 2013.

LITZ, R. A. Two sides of a one-sided phenomenon: conceptualizing the family business and business family as a möbius strip. Family Business Review, v. 21, n.3, p. 217-236, set. 2008.

LITZ, R. A.; KLEYSEN, R.F. Your Old Men Shall Dream Dreams, Your Young Men Shall See Visions: Toward a Theory of Family Firm Innovation with Help from the Brubeck Family. Family Business Review, v. 14, n.4, p. 335-352, dez. 2001.

LITZ, R. A.; PEARSON, A. W.; LITCHFIELD, S. Charting the Future of Family Business Research: Perspectives from the Field. Family Business Review, v. 25, n. 1, p. 16-32, 2012.

LLACH, J.; NORDQVIST, M. Innovation in family and non-family businesses: a resource perspective. International Journal of Entrepreneurial Venturing, v. 2, n. 3/4, p. 381-399, set. 2010.

MAHMOUD-JOUINI, S.; BLOCH, A.; MIGNON, S. Capacités d'innovation des entreprises familiales pérennes : proposition d'un cadre théorique et méthodologique. Revue Française de Gestion, v. 50, n. 200, p. 111-126, 2010.

MAHMOUD-JOUINI, S.; MIGNON, S. Entrepreneuriat familial et stratégies de pérennité : contribuition au concept d'innovation prudentielle. Management International, v. 14, n. 1, p. 25-41, jan. 2009. 
MOSS, T. W.; PAYNE, G. T. ; MOORE, C. B. Strategic Consistency of Exploration and Exploitation in Family Businesses. Family Business Review, no prelo, 2014.

NORDQVIST, M.; WENNBERG, K.; BAU, M.; HELLERSTEDT, K. An entrepreneurial process perspective on succession in family firms. Small Business Economics, v. 40, n. 4, p. 1087-1122, mai. 2013.

PANUWATWANICH, K; STEWART, R. A.; MOHAMED, S. Validation of an empirical model for innovation diffusion in Australian design firms. Construction Innovation, v. 9, n. 4, p. 449-467, dez. 2009.

ROESSL, D.; FINK, M.; KRAUS, S. Are family firms fit for innovation? Towards an agenda for empirical research. International Journal of Entrepreneurial Venturing, v. 2, n. 3/4, p. 366380, set. 2010.

SCHUMPETER, J. A. Teoria do desenvolvimento econômico: uma investigação sobre lucros, capital, crédito, juro, e o ciclo econômico. São Paulo: Nova Cultural, 1997.

SHARMA, P.; CHRISMAN, J. J.; GERSICK, K. E. 25 Years of Family Business Review: Reflections on the past and perspectives for the future. Family Business Review, v. 25, n. 1, p. 5-15, mar. 2012. THUHANG, T.; JONES, J.A. A conceptual model of learning culture and innovation schema, Competitiveness review: An International Business journal, v.18, n.3, p.287-299, 2008.

WATSON, T. J. Entrepreneurship in Action: Bringing Together the Individual, Organizational and Institutional Dimensions of Entrepreneurial Action. Entrepreneurship \& Regional Development, v. 25, n. 5-6, p. 404-422, ago. 2013.

WEBB, J. W.; KETCHEN JUNIOR, R.; IRELAND, R. D. Strategic entrepreneurship within familycontrolled firms: opportunities and challenges. Journal of Family Business Strategy, v.1, n.2, p. 67-77, jun. 2010.

YIN, R. K. Estudo de caso: planejamento e métodos. 3. ed. Porto Alegre: Bookman, 2005. ZELLWEGER, T. M.; NASON, R. S.; NORDQVIST, M. From Longevity of Firms to Transgenerational Entrepreneurship of Families: Introducing Family Entrepreneurial Orientation. Family Business Review, v. 25, n. 2, p. 136-155, jun. 2012.

ZHAO, F. Exploring the sinergy between entrepreneurship and innovation. International Journal of Entrepre

d. Porto Alegre: Bookman, 2001. 